Dicle Tıp Dergisi / Dicle Med J (2019) 46 (3) : 435 - 441

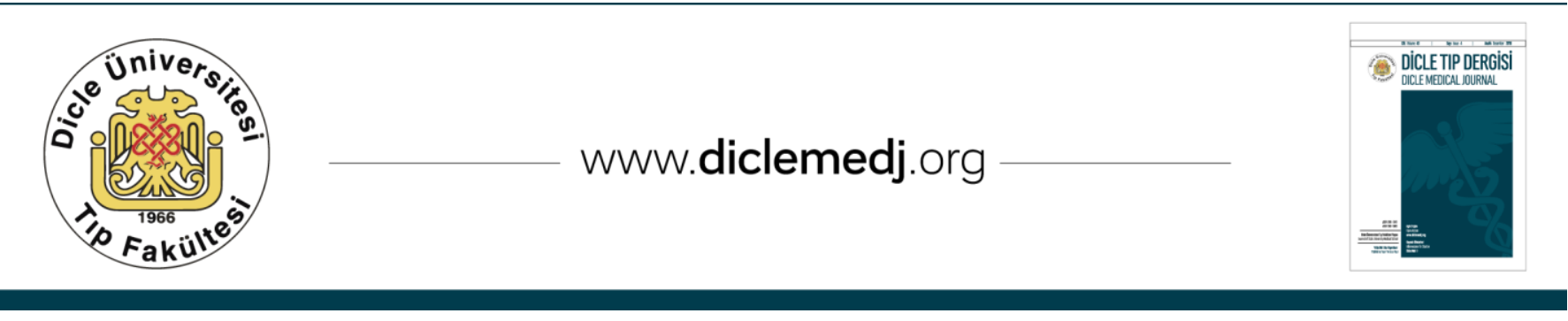

Özgün Araștırma / Original Article

\title{
Heliks-Antiheliks Ayırma Tekniği ile Otoplasti Sonuçlarımız
}

\author{
Secaattin Gülşen ${ }^{1}$, Saffet Ulutaş ${ }^{2}$
}

1 Özel HATEM Hastanesi KBB Kliniği ORCID: 0000-0003-0687-6057

2 Dr.Ersin Arslan Eğitim ve Araștırma Hastanesi Plastik Estetik ve Rekonstruktif Cerrahi Kliniği ORCID: 0000-0002-8214-4002

Geliş: 22.02.2019; Revizyon: 19.06.2019; Kabul Tarihi: 03.07.2019

$\ddot{0} z$

Amaç: Yazarlar bu çalışmada heliks ve antiheliksi tam kat kıkırdak kesisi ile ayırarak kepçe kulak onarımı yapılan hastaların cerrahi sonuçlarını değerlendirmeyi amaçlamışlardır.

Yöntemler: Ağustos 2016 ve Ocak 2019 yılları arasında heliks ve antiheliksi ayırarak kıkırdak çıkarma işlemi yapmadan lokal anestezi altında emilebilir dikiş ile kepçe kulak onarımı ameliyatı yapılan 39 hasta çalışmaya dahil edildi. Ameliyat sonrası sonuçlar ve komplikasyonlar kayıt altına alındı. Ameliyat sonrası 6. ayda hastalara kepçe kulak onarımı işleminin sonucu hakkında ne düşündükleri soruldu ve 'çok kötü, kötü, kabul edilebilir, iyi ve çok iyi' cevaplarından birisini seçmeleri istendi. İyi ve çok iyi cevapları tatmin edici olarak değerlendirildi. Hastaların cerrahi sonuçları, komplikasyonları ve hasta tatmini geriye dönük olarak değerlendirildi.

Bulgular: Çalışmaya dahil edilen toplam 29 hastanın 17 si $(\% 58,6)$ bayan, 12 si $(\% 41,4)$ erkekti. Hastaların $21(\% 72,4)$ inde iki taraflı kepçe kulak onarımı yapılırken, $8(\% 27,6)$ hastada tek taraflı kepçe kulak onarım ameliyatı yapıldı. Toplamda 50 adet kepçe kulak onarımı yapıldı. Hastaların yaşları 14 ile 27 arasında değişmekte olup ortalama $21.2 \pm 5.7$ yıl idi. Ameliyat sonrası takip süresi en az 12 ay en fazla 28 ay arasında değişmekle beraber ortalama 15.6 ay idi. Erken dönem komplikasyonları olarak; 4 (\%8) vakada hematom, 2 (\%4)vakada yara ayrılması ve bir (\%2)vakada yara yeri enfeksiyonu izlendi. Hastaların ameliyat sonucundan tatmin olma oranı \%93,1 (29 hastanın 27 si) idi. Uzun dönem takip sürecinde 1 (\%2)kulakta sadece üst polde olmak üzere kısmi nüks izlendi.

Sonuç: Heliksi tamamen serbestleştirerek emilebilir dikiş ile kepçe kulak onarımı ameliyatı dikiş materyaline bağlı komplikasyonlardan kaçınmayı sağlayan, uzun dönemde cerrahi başarı oranı yüksek olan ve yüksek hasta memnuniyet oranı sunan alternatif bir tekniktir.

Anahtar kelimeler: Kepçe kulak, Otoplasti, Heliks, Antiheliks, Dış kulak.

DOI: $10.5798 /$ dicletip. 620375

Yazışma Adresi / Correspondence: Secaattin Gülşen, Özel HATEM Hastanesi KBB KliniğiAllaben mah. Kemal Köker Cad. No:41 (Ulu Camii Karşısl) Şahinbey / Gaziantep, Türkiye e-mail: drsecaattingulsen@gmail.com 


\title{
Our Otoplasty Results with Helix-Antihelix Separation Technique
}

\begin{abstract}
Objective: In this study, the authors aimed to evaluate the surgical results of the patients who underwent prominent ear surgery by separating the helix from antihelix via full-thickness cartilage incision.

Method: Between August 2016 and January 2019, 39 patients with prominent ear deformity who underwent surgery under local anesthesia with absorbable suturing were included in the study. Postoperative results and complications were recorded. At the postoperative 6th month, the patients were asked what they thought about the result of their surgery. Patients were requested to choose one of the answers among the "very bad, bad, acceptable, good and very good" that best suits their expectations about the surgery. Good and very good answers were evaluated as satisfactory. Surgical results, complications and patient satisfaction were evaluated retrospectively.

Results: Of the 29 patients included in the study, 17 (58.6\%) were female and 12 (41.4\%) were male. While 21 $(72.4 \%)$ of the patients underwent bilateral prominent ear correction surgery, 8 (27.6\%) of the patients underwent unilateral prominent ear correction surgery. In total, 50 prominent ears were operated. The age of the patients ranged from 14 to 27 years and the mean age was $21.2 \pm 5.7$ years. The postoperative follow-up period ranged from 12 months to 28 months, with an average of 15.6 months. As early postoperative complications; 4 (8\%) cases had a hematoma, $2(4 \%)$ cases had wound separation and $1(2 \%)$ had wound infection. The satisfaction rate of the patients was $93.1 \%$ (27 of 29 patients). In the long-term follow-up, partial recurrence was observed in only one (2\%) auricle in the upper pole.

Conclusion: Helix-free prominent ear correction with absorbable sutures is an alternative technique that allows avoiding complications related to the suture material, has a high surgical success rate in the long term and provides a high patient satisfaction rate.
\end{abstract}

Keywords: Prominent ear, Otoplasty, Helix, Antihelix, External ear.

\section{GíRiş}

Kulak kepçesi cilt, kıkırdak ve yağ dokularının oluşturduğu konka, heliks, antiheliks, tragus ve lobül olmak beş temel anatomik bölgeden oluşan esnek bir yapıdır. Kepçe kulak oluşumunun en sık nedeni konkanın fazla gelişmesi ve antiheliksin yetersiz gelişimi veya her ikisinin birlikte görülmesidir. Toplumda görülme sıklığı \%5 olup, etkilenen bireylerde psikososyal hastalıklara neden olabilir ${ }^{1,2}$. Kulak kepçesinde doğal görünen bir antiheliks kıvrımı oluşturmak için kazıma, bükme, dikiş atma, çizme veya yeniden konumlandırma yöntemleri veya bunlarm kombinasyonlarma dayanan çeşitli sonuçlara sahip birçok farklı cerrahi teknik tanımlanmıştır ${ }^{3}$. Dikiş ve kıkırdak kesme teknikleri ile kepçe kulak onarımı güncel olarak dünya genelinde en sık kullanılan iki ana cerrahi yaklaşımdır 4,5 . Heliksin antiheliksten ayrılması kavramı, Chongchet tarafından tarif edilmiștir. Aurikula ön yüzeyine kazıma, kısmi ya da tam kat kıkırdak çıkarma gibi yaklaşımlar yapılmış bu tekniklerde doğal olmayan görünüm, pürüzlü görünüm ve antihelikste keskin kıvrımlar gibi sorunlarla karşılaşılmıştır ${ }^{6} . \quad \mathrm{Bu}$ çalışmada yazarlar aurikula arkasından bieliptik cilt kesisi ve çıkarımı yaparak, heliks ve antiheliksi tam kat kıkırdak insizyonu ile ayırdıktan sonra emilebilir dikiş kullanarak Mustarde matris dikiş tekniği ile yeni antihelikal katlantıyı oluşturarak kepçe kulak onarımı yaptıkları 39 hastanın sonuçlarını sunmuşlardır.

\section{YÖNTEMLER}

$\mathrm{Bu}$ retrospektif çalışmada Ağustos 2016 ve Ocak 2019 tarihleri arasında özel bir hastane ve üçüncü basamak bir hastanenin KBB ve plastik cerrahi polikliniklerine kepçe kulak şikayeti ile başvuran ve bu nedenle ameliyat edilen 39 hasta dahil edilmiștir. Çalıșmaya alınan hastalarm hepsi birincil ameliyatlar olup 
revizyon ameliyatlar çalışmaya dahil edilmemiştir. Takip edilemeyen hastalar da çalışmaya dahil edilmemiştir. Hastalardan ameliyat sonuçlarının kişisel bilgileri gizli tutulmak suretiyle bilimsel amaçlı kullanılacağına dair bilgilendirme içeren yazılı onam ve çalışmaya başlanılmadan önce yerel etik kurul onayı alınmıştır. Bütün hastaların ameliyat öncesi, ameliyat anında ve ameliyat sonrası altıncı ayda önden, arkadan ve yandan fotoğrafları çekilmiştir. Ameliyat öncesi rutin KBB muayeneleri ve kulak kepçesinin anatomik yapıları değerlendirilip, bu doğrultuda ameliyat öncesi planlamalar yapılmıştır.

Ameliyat edilen hastaların tümünde aynı cerrahi teknik kullanılmıştır ve tüm hastalar lokal anestezi altında ameliyat edilmiştir. Ameliyat öncesinde kulak kepçesi alt, üst, ön ve arka bölgesi olmak üzere 4 kadran ve kulak arkasındaki kesi hattı ve kulak kepçesinin ön yüzeyine $20 \mathrm{mg} / \mathrm{ml}$ lidokain hidroklorür ve $0.0125 \mathrm{mg} / \mathrm{ml}$ epinefrin infiltrasyonu yapılmıştır. Aurikula arkasındaki bieliptik cilt insizyon hattı işaretlendikten sonra yeni oluşturulacak antihelikal kıvrım ve heliksi serbestleştirmek için yapılacak kıkırdak kesi hattı boya kalemi ile çizilmiştir (Şekil-1A ve 1B). Metilen mavisi ve iğne kullanılarak heliksi tamamen antiheliksten ayırma için yapılacak kıkırdak insizyonu hattı işaretlendi. Aurikula arkasından bieliptik kesi ile cilt çıarıldıktan sonra aurikula arka yüzeyi cilt altından perikondrium üstündeki plandan flep serbestleștirildi (Şekil-2A). Bu teknikte emilebilir dikiş kullanıldığından dolayı perikondrium üzerinden flep elevasyonu ile kıkırdak katlandıktan sonra ameliyat sonrası sineşi oluşuması sağlanarak nükslerin oluşumunun engellenmesi planlanmıştır. Aurikula arka yüzeyindeki perikondrium üstü flep kaldırıldıktan sonra heliksin lateral sınırı boyunca üst kutuptan başlayarak kuyruğuna kadar metilen mavisi ile işaretlenen antihelikal katlantının planlandığı hattan tam kat kıkırdak insizyonu yapılarak aurikula ön yüzeyinde perikondrium altındaki plandan cilt flebi kaldırıldı (Şekil-2B). Bu işlem sonrası heliks antiheliksten tamamen ayrlarak serbestleştirildi. Daha sonra planlanan şekilde antiheliksi oluşturmak için klasik Mustarde tekniğinde tariflendiği üzere 4.0 emilebilir dikiş kullanılarak üç adet matris dikiş ile kulak kepçesinden kıkırdak çıkarımı yapılmaksızın yeni şekli verildi (Şekil-3A). Bu teknikte kıkırdak üzerinde herhangi bir törpüleme, kısmi yada tam kat bir kıkırdak doku çıkarımı işlemi yapılmadığından antiheliksin pürüzsüz ve doğal bir görünüme sahip olması sağlandı (Şekil-3B). Son olarak kanama kontrolü yapıldıktan sonra ciltteki kesi hattı4.0 prolen dikiş ile cilt altı sürekli dikiş ile kapatıldı. Aurikulaya verilen yeni șekil antibiyotikli pomad emdirilmiş pamuk şeritlerle desteklenerek sargılı pansuman ile kapatıldı.

Hastalar ameliyat sonrası aynı günde taburcu edildiler ve iki günde bir olmak üzere pansuman için kontrol muayenelerine çağrıldılar. Ameliyat sonrası ilk hafta boyunca analjezik ve antibiyotik (AmoksisilinKlavulanik Asit) tedavisi verilen hastaların ilk haftanın sonunda cilt kesisini kapatmak için kullanılan prolen dikiş alındı. Hastalara iki hafta daha boyunca gece gündüz sürekli elastik bandaj ile kulaklarını sarmaları önerildi, daha sonra ikinci aya kadar verilen yeni șekli korumak amacı ile sadece geceleri kulaklarını elastik bandaj ile sarmaları önerildi. Hastalar rutin olarak ameliyat sonrası altıncı ayda ve birinci senede kontrollere çağrıldılar. Altıncı aydaki kontrollerde hastalara kepçe kulak ameliyatlarının sonuçlarını değerlendirilmesi istendi. Hastalardan "çok kötü, kötü, kabul edilebilir, iyi ve çok iyi" cevaplarından birisini seçmeleri istendi. Bu çalışmada iyi ve çok iyi cevapları tatmin edici olarak değerlendirildi.

Ameliyat sonrası komplikasyonlar, cerrahi sonuçlar ve hasta memnuniyet seviyesi geriye dönük olarak incelendi. 


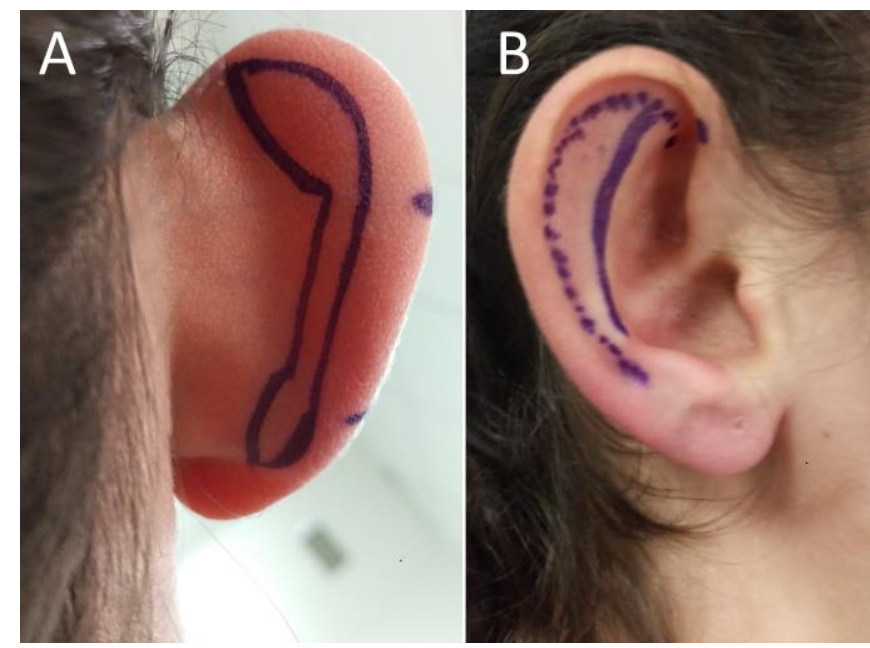

Şekil-1A: Bieliptik cilt kesi hattının işaretlenmesi.

Şekil-1B: Oluşturulacak antiheliks kıvrımının ve heliksi ayırmak için yapılacak kıkırdak kesi hattının işaretlenmesi, noktalı çizgi kesi hattını, devamlı çizgi sütür hattını göstermektedir

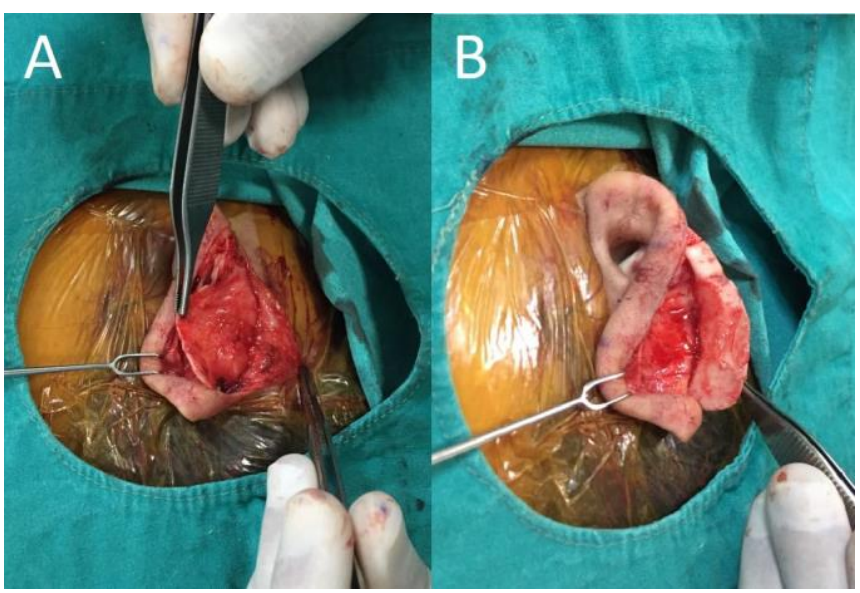

Şekil-2A: Aurikula arka yüzeyde sineşi oluşturmak için perikondrium üzerindeki plandan diseksiyon.

Şekil-2B: Aurikula ön yüzeyde perikondrium altındaki plandan diseksiyon.

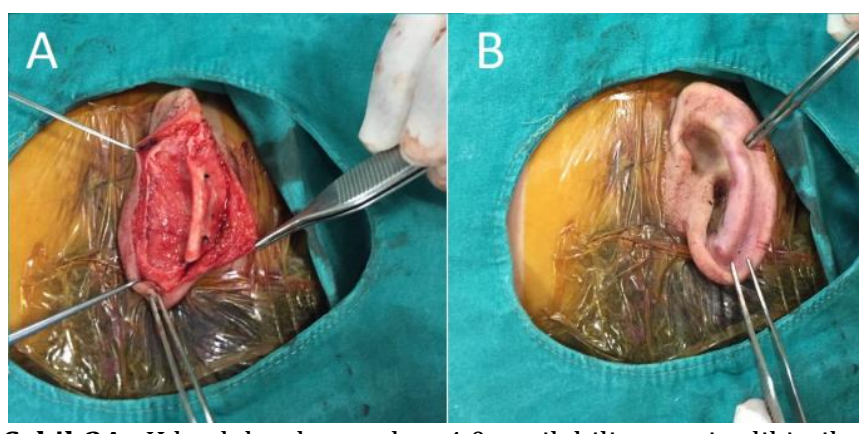

Şekil-3A: Kıkırdak çıkarmadan 4.0 emilebilir matris dikiş ile antiheliks kıvrımının oluşturulması

Şekil-3B: Doğal görünümlü ve pürüzsüz antiheliks kıvrımının ameliyat anındaki görünümü

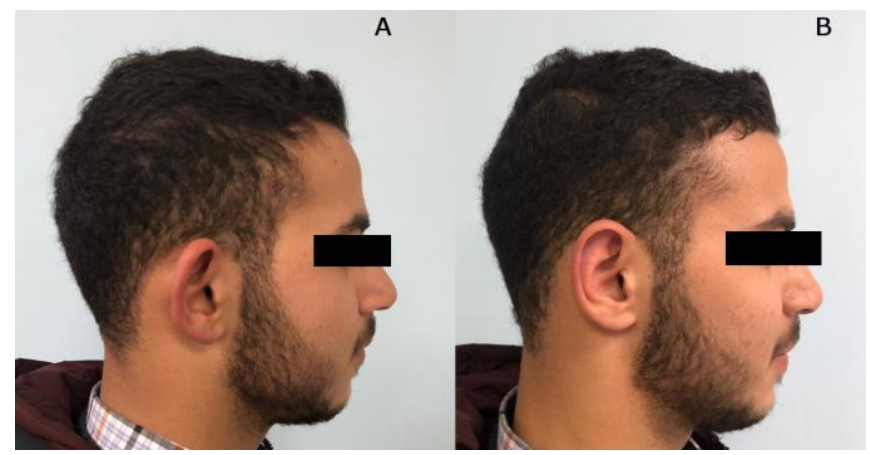

Şekil-4A: Kepçe kulak deformitesinin ameliyat öncesi lateral görünümü

Şekil-4B: Otoplasti sonrası 6. Aydaki doğal ve pürüzsüz antiheliks kıvrımı görünümü

\section{BULGULAR}

Toplamda 29 hastanın 50 kulağı ameliyat edildi. Çalışmaya dahil edilen hastaların yaşları 14 ile 27 yaş arasında (ortalama-standart sapma; $21.2 \pm 5.7$ yll) idi. Olgularm 17 'si $(\% 58,6)$ bayan, 12 'si $(\% 41,4)$ erkekti. İki taraflı kepçe kulak onarımı $21(\% 72,4)$ hastaya yapılırken, 8 $(\% 27,6)$ hastada ise tek taraflı kepçe kulak onarım ameliyatı yapıldı. Olguların 22 $(\% 75,8)$ sinde sorun antiheliksin yetersiz gelişmesinden kaynaklanmakta iken, 7 $(\% 24,2)$ olguda antiheliks gelişim yetersizliğine ek olarak aurikular konkanın yayvan ve derin olması ek sorun oluşturmaktaydı. Ameliyat sonrası takip süresi 12 ay ile 28 ay arasında değişmekle beraber ortalama 15.6 aydı. Hastalara ait demografik ve klinik özellikler tablo-1'de sunulmuştur.

Tablo-1. Hastaların demografik ve klinik özellikleri

\begin{tabular}{|c|c|}
\hline \multicolumn{2}{|c|}{ Demografik ve klinik özellikler } \\
\hline Yaş ortalaması ve aralığı (Yıl) & $21,2(14-27)$ \\
\hline \multicolumn{2}{|l|}{ Cinsiyet } \\
\hline Erkek & $12(\% 41,4)$ \\
\hline Bayan & $17(\% 58,6)$ \\
\hline \multicolumn{2}{|l|}{ Otoplasti ameliyatı } \\
\hline Tektaraflı & $8(\% 27,6)$ \\
\hline Çifttaraflı & $21(\% 72,4)$ \\
\hline Ortalamatakipsüresi(Ay) & 15,6 \\
\hline
\end{tabular}


Ameliyat sonrası erken dönemde 1'i aurikula ön yüzeyinde 3'ü arka yüzeyde olmak üzere toplam 4 (\%8) olguda hematom meydana geldi. Oluşan hematom enjektör yardımı ile boşaltıldı baskılı pansuman sonucu 1 hafta içerisinde kendiliğinden sorunsuz bir şekilde iyilești. Ameliyat sonrası 1. haftada cilt dikişi alındıktan sonra 2 (\%4) olguda cilt gerginliğe bağlı aurikula üst kısımda yara dudaklarında küçük ayrışma oluştu, steril strip ile yapıștırıldı, sekonder iyileşmeye bırakıldı ve bir hafta sonra iyileştiği gözlendi. Yara yerinde yumuşak doku enfeksiyonu gelişen 1 (\%2) olguda, pansuman ve sistemik antibiyotik tedavisine ek lokal antibiyotikli pomad ile enfeksiyon kıkırdak dokuya yaylmadan tedavi edildi. 1 (\%2)olguda aurikula ön yüzeyde epidermolizis bülloza meydana geldi, pansuman tedavisi ile bir hafta içinde geriledi.

Ameliyat sonrası 6. ayda yapılan kontrollerde hastalar ameliyat sonuçları hakkında "çok kötü ve kötü" şeklinde bir görüş bildirmediler. İki kulak arasında hafif asimetri gözlemlenen 1 (\%2) hasta ve kulak kepçesi üst kutupta hafif derecede nüks izlenen 1 (\%2) hasta olmak üzere toplam iki hasta ameliyat sonuçlarını "kabul edilebilir" olarak niteledi. Bu iki hastaya tekrar cerrahi önerildi fakat hastalar ameliyatı kabul etmediler. Geriye kalan 27 hastanın 7 si ameliyat sonuçlarını "iyi" olarak nitelerken 20 hasta ameliyat sonuçları hakkında "çok iyi" olarak görüş bildirdiler. Sonuç olarak 29 hastanın 27'si $(\% 93,1)$ ameliyat sonuçlarından tatmin olduklarını belirttiler. Şekil-4 te görülebildiği üzere otoplasti sonrası 6. ayda yapilan kontrolde oluşturulan antiheliks kıvrımının doğal ve pürüzsüz olduğu izlenebilmektedir.Çalışmamızdaki hastaların hiç birinde takip süreci boyunca kalıcı dikişlerde karşılaşılan dikiş atılımı ve dikiş materyaline bağlı yabancı cisim reaksiyonu gibi komplikasyonlar izlenmedi. Ek olarak cilt kesisine bağlı hiçbir hastada hipertorfik yara iyileşmesi sonucu skar oluşumu gözlenmedi. Ameliyat sonrası oluşan erken ve geç dönem komplikasyonlar tablo-2'de özet halinde sunulmuştur.

Tablo-2. Ameliyat sonrası komplikasyon oranları

\begin{tabular}{lcc} 
Komplikasyonlar & $\begin{array}{c}\text { Evet } \\
\text { n, \% }\end{array}$ & $\begin{array}{c}\text { Hayır } \\
\text { n, \% }\end{array}$ \\
Hematom & 4,8 & 46,92 \\
Yarakenarlayrılması & 2,4 & 48,96 \\
Yarayerienfeksiyonu & 1,2 & 49,98 \\
Hipertrofikyaraiyileșmesi & 0,0 & 100 \\
Epidermolizisbülloza & 1,2 & 49,98 \\
Asimetri & 1,2 & 49,98 \\
Nüks & 1,2 & 49,98 \\
\hline
\end{tabular}

\section{TARTIŞMA}

Kepçe kulak onarımı için günümüze kadar birçok cerrahi teknik tanımlanmış olsada, tanımlanan hiçbir teknik tek başına tüm kepçe kulak olgularının onarımı için yeterli olmamıştır 1,2,5-7. Kepçe kulak olgularında deformitenin sebebi ve şiddeti her hastada farklı boyutlarda olabileceği için standart bir cerrahi teknik yerine bazen kombine yaklaşımlara ihtiyaç duyulmaktadır². Kepçe kulak onarımı hedefleri arasında mastoid düzlem ile heliks arasındaki açıyı 40 derecenin altında tutarak heliks ile kafatası arasındaki mesafeyi $1.5-2 \mathrm{~cm}$ ye kadar yaklaştırmak ve iki kulak arasındaki simetriyi sağlamak yer almaktadır. Simetriyi sağlamak kepçe kulak ameliyatının en temel ve sonuca doğrudan etki eden en önemli aşamasıdır ${ }^{8}$.

Kepçe kulak deformitesine eşlik eden konka patolojilerini düzeltmek için dikiş, kıkırdak kesisi ve kıkırdak çıkarılması üç ana teknik tanımlanmıştır. Furnas dikiş tekniği bunların en popüler olanıdır, bu teknikte kalıcı dikişler kullanılarak konka kıkırdağı mastoid üzerindeki fasyaya dikilir. Genellikle sonuçlar hayli tatmin edici olmakla beraber bu teknikte postaurikuler sulkus kaybolur. Konkal kıvrımın fazla olduğu hastalar içinde kıvrımı azaltmak amacıyla konkal kıkırdaktan bazen cildinde 
eşlik ettiği tam kat kıkırdak çıkarılması veya kıkırdak kesisi yapılmaktadır ${ }^{7,9}$.

Antiheliks kıvrımını oluşturmak için tanımlanan teknikler başlıca dikiş ile onarım teknikleri, kıkırdak kesi ve törpüleme işlemleri ve bunların kombinasyonu olmak üzere üç ana başlık altında sınıflandırılabilir. Birçok yazar antiheliks kıvrımını oluşturmak için zaman alan ve aynı zamanda doğal olmayan görünüme sahip antiheliks kıvrımı ile sonuçlanabilen kıkırdak törpüleme, kısmi ya da tam kat kıkırdak çıkarımı gibi cerrahi teknikler tanımlamıştır ${ }^{9,10}$. Özellikle kalın aurikula kıkırdağı olan hastalarda ameliyat sonrası uzun dönemde kıkırdak hafızasına bağlı hastalığın nüksü izlenebilmektedir. Tam kat kıkırdak çıkarılması ve dikiş kullanılarak sonra oluşturulan antiheliks kıvrımı bazen çok keskin ve doğal olmayan hatlara sahip olmaktadır bu durumhastaların ameliyat sonrası tatminini azaltmaktadır.

Chongchet'in tarif ettiği cerrahi yaklaşıma göre aurikula ön yüzüne ulaşmak amacıyla heliks ile antiheliks arasından bir kesi yapılır ve aurikula kıkırdağı ön yüzü tam kat olmayan kesilerle veya törpülemelerle zayıflatılarak antiheliks kıvırımı oluşturulmaya çalıșılır. Tanımlanan bu yaklaşımla ameliyat edilen hastalarda ameliyat sonrası \%89'unda estetik açıdan tatminkar bir sonuç elde edildiği bildirilmiştir. Yine aynı çalışmada bu teknik ile hastaların \%81'inde doğal görünüme sahip pürüzsüz bir antiheliks kıvrımı elde edildiği belirtilmiştir ${ }^{11}$.

Bizim çalışmamızda kullandığımız teknik son derece basit, kısa öğrenim eğrisine sahip, uzun ameliyat süreleri gerektirmeyen ve emilebilir dikiş kullanılarak gerçekleştirilebilinen bir yaklaşımdır. Valentenin tanımladığı ve son zamanlarda yaygınlaşma eğiliminde olan bieliptik cilt kesisi ile cilt çıkararak heliksi tamamen ayırıp serbestleștirmek ilk bakıșta çok girişimsel bir teknik gibi görülebilmesine rağmen lokal anestezi altında yapılabilen uygulaması son derece basit ve geniş flep kaldırılması nedeni kapatılan yara yerinde erken dönemde nükslere sebeb olabilen gerginliğe neden olmaması nedeniyle son derece önemli avantajlara sahip olan bir tekniktir ${ }^{10,12}$. Valente tanımladığ $\breve{l}$ teknik ile heliks ve antiheliksi ayırarak gerçekleştirdiği ameliyatlarını sunduğu makalesinde 3.5 ile 10 yıl arasında değişen ortalama 4.3 yıllık gibi uzun bir takip süresi sonrası hiçbir olguda nüks belirtmemiştir aynı zamanda\%98,3 gibi yüksek bir hasta memnuniyet oranı bildirmiștir ${ }^{12}$.

Otoplastide dikiş materyallerini kıyaslayan bir çalışmaya göre Monocryl kullanılan grupta hastaların \%8,5' inde, PDS kullanılan hastların $\% 11,1^{\prime}$ inde aurikula üst kısımda nüks izlendiğinden hastaların cerrahi sonuçtan tatmin olmadığı bildirilmiştir ve bu hastalar tekrar ameliyat edilmiştir. Yine aynı makalede Mersilen dikiş kullanılan grupta hastaların hiçbirinde nüks olmamasına rağmen hastaların \%2,6' sında dikiş aurikula cildinden dışarı atılıma uğramıștır ve bu dikişler alınmıștır. $\mathrm{Bu}$ çalışmada yazarlar antihelikal kıvrımın oluşturulmasında Mersilen dikiş kullanımının daha az komplikasyon oranı ile nüksü engellediğini bildirmişlerdir ${ }^{13}$.

Sonuç olarak günümüzde kepçe kulak deformitesi onarımı için deformitenin tipine, eşlik eden ek sorunlara ve şiddetine bağlı olarak çeşitli cerrahi teknikler tanımlanmıştır. Heliksi tamamen ayırıp serbestleştirerek kıkırdak çıkarmadan antiheliks kıvrımını emilebilir dikiş ile doğal ve pürüzsüz olarak oluşturmak son derece güvenli ve uzun dönemde çok düşük nüks oranları sağlayan alternatif bir tekniktir. Bu teknikle ameliyat ettiğimiz hastaların şuana kadarki sonuçları tatmin edici olmasına karşın, örneklem büyüklüğünün literatürdeki çalışmalara kıyasla daha küçük olması çalışmamızın kısıtlayıcı yanlarından birisidir. Diğer otoplasti tekniklerine kıyasla daha yeni olan bu tekniğin geçerliliğini doğrulamak için daha uzun takip süreleri ve daha büyük örneklem boyutuna 
sahip prospektif çalışmaların yapılması belirleyici olacaktır.

Çıkar Çatışması: Yazar bu yazının hazırlanması ve yayınlanması hususunda çıkar çatışması olmadığını beyan etmiştir.

Finansal Destek: Çalışmamız, herhangi bir fondan maddi destek almamıştır.

Declaration of Conflicting Interests: The authors hereby declare that they have no conflict of interest.

Financial Disclosure: No financial support was received.

\section{KAYNAKLAR}

1. Kuşcu 0,Önay Ö, Günaydın RÖ, et al. Otoplasty Outcomes and Results: Does Furnas Setback Suture Affect Complication Rates? Turk Arch Otolaryngol. 2014; 52: 52-6

2. Songu M. Kombine Mustardé ve Furnas tipi otoplastisi: 85 hastalık deneyim. J Med Updates 2013; 3: 129-34.

3. Janis JH, Rohrich RJ, Gutowski KA. Otoplasty. Plast Reconstr Surg 2005; 115: 60-72.
4. Mustardé JC. The treatment of prominent ears by buried mattress sutures: a ten-year survey. Plast Reconstr Surg. 1967; 39: 382-6.

5. Converse JM, Wood-Smith D. Technical details in the surgical correction of the lop ear deformity. Plast Reconstr Surg. 1963; 31: 118-28.

6. Chongchet V. A method of antihelix reconstruction. Br J Plast Surg. 1963; 16: 268-72.

7. Öktem F, Gözen ED. Otoplasti. Turkiye Klinikleri J E.N.T.2014; 7: 80-8

8. Strychowsky JE, Moitri M, Gupta MK, et all. Incisionless otoplasty: a retrospective review and outcomes analysis. Int J Pediาatr Otorhinolaryngol 2013; 77: 1123-7.

9. Schneider AL, Sidle DM. Cosmetic Otoplasty. Facial Plast Surg Clin North Am. 2018; 26: 19-29.

10. Ahmed $M$, Alkhalaf $H$, Ibrahim E. Helix free otoplasty for correction of prominent ear. Asian J Surg. 2018; 22: 30541-4.

11. Janis JE, Rohrich RJ, Gutowski KA. Otoplasty. Plast Reconstr Surg 2005; 115: 60-72.

12. Valente AS. Separating the Helix From the Antihelix: A New Concept in Prominent Ear Correction. Aesthetic Surgery Journal. 2010; 30: 139-53

13. Maslauskas $\mathrm{K}$, Astrauskas T, Viksraitis $\mathrm{S}$, et all. Comparison of otoplasty outcomes using different types of suture materials. Int Surg. 2010; 95: 88-93. 